\title{
Response of Populus euphratica Oliv. sap flow to environmental variables for a desert riparian forest in the Heihe River Basin, Northwest China
}

\author{
LI Wei ${ }^{1,2,3}$, SI Jianhua ${ }^{2 *}$, YU Tengfei ${ }^{2}$, LI Xiaoyan ${ }^{1,3}$ \\ ${ }^{1}$ College of Resources Science and Technology, Beijing Normal University, Beijing 100875, China; \\ ${ }^{2}$ Cold and Arid Regions Environmental and Engineering Research Institute, Chinese Academy of Sciences, Lanzhou 730000, \\ China; \\ ${ }^{3}$ State Key Laboratory of Earth Surface Processes and Resource Ecology, Beijing Normal University, Beijing 100875, China
}

Abstract: Being an important desert riparian forest in the lower reaches of the Heihe River Basin Populus euphratica Oliv. forest functions as a natural barrier in maintaining and preserving the stability of local oases. Accordingly, accurately estimating the water use of $P$. euphratica is important for vegetation protection and water resource allocation. To date, little data are available for evaluating the hysteretic effects between sap flow and environmental variables, and for estimating the water use of desert riparian forest. In this study, we measured the sap flow velocity $\left(V_{s}\right)$ of $P$. euphratica using the heat ratio method during the growing season of 2012. Based on the response of $V_{s}$ to solar radiation $\left(R_{s}\right)$ and vapor pressure deficit $(V P D)$, we estimated the hourly $V_{s}$ and daily $V_{s}$ using the multivariable linear regression and a modified Jarvis-Stewart (JS) model, respectively. Hysteretic response of $V_{s}$ to environmental variables was then evaluated using a sap flow model. We found the thresholds of $V_{s}$ responses to $R_{s}$ and VPD at both hourly and daily scales during the growing season, and successfully estimated the seasonal variations of hourly $V_{s}$ and daily $V_{s}$ using the JS model. At an hourly scale, the maximum $V_{s}$ occurred earlier than the maximum VPD by approximately $0.5 \mathrm{~h}$ but later than the maximum $R_{s}$ by approximate $1.0 \mathrm{~h}$. At a daily scale, the maximum $V_{s}$ lagged behind the maximum VPD by approximately $2.5 \mathrm{~h}$ while occurred earlier than the maximum $R_{s}$ by approximately $2 \mathrm{~h}$. However, hysteretic response of $V_{s}$ was weakened when $R_{s}$ and VPD were measured together using the JS model at both hourly and daily scales. Consequently, short-term and intensive field campaigns, where $V_{s}$ and environmental variables can be measured, may be used to estimate short-run sap flow and stand transpiration using only two environmental variables.

Keywords: sap flow; solar radiation; vapor pressure deficit; Jarvis-Stewart model; hysteresis

Citation: LI Wei, SI Jianhua, YU Tengfei, LI Xiaoyan. 2016. Response of Populus euphratica Oliv. sap flow to environmental variables for a desert riparian forest in the Heihe River Basin, Northwest China. Journal of Arid Land, 8(4): 591-603. doi: $10.1007 / \mathrm{s} 40333-016-0045-4$

The exchange of water flux between vegetation and the atmosphere is an important function for both energy transferring and hydrological cycling in forest ecosystems. Accordingly, it is critical to determine water budgets of woody forests, water use of individual trees and water exchanges of stands, either through direct measurements or model predictions (Komatsu et al., 2006; Whitley et al., 2009). Techniques in determining sap flow are characterized by practicality and repeatability.

*Corresponding author: SI Jianhua (Email: jianhuas@1zb.ac.cn)

Received 2015-11-04; revised 2016-01-25; accepted 2016-02-02

(C) Xinjiang Institute of Ecology and Geography, Chinese Academy of Sciences, Science Press and Springer-Verlag Berlin Heidelberg 2016 
They must provide accurate and instantaneous estimations of water flux for plants in their entirety (e.g. trunk, leaves and roots) over relative short-time scales (Dragoni et al., 2009; Steppe et al., 2010). Such techniques are widely used to monitor the water use of tree or stand in various ecosystems for a long period (O’Grady et al., 2008; Sánchez-Costa et al., 2015). However, they are applied to forest stands in arid and semi-arid regions only in recent years (Du et al., 2011; Zheng and Wang, 2014).

Sap flow velocity $\left(V_{s}\right)$, which is similar to plant water use, is driven by available energy, evaporative demand and water availability. For example, David et al. (2004) reported a progressive loss in $V_{s}$ sensitivity to solar radiation $\left(R_{S}\right)$ from morning to afternoon. $V_{s}$ increases with increasing vapor pressure deficit $(V P D)$ rates following times of higher water availability, while $V_{s}$ will be saturated above a certain VPD threshold to prevent catastrophic loss of xylem functions (Granier et al., 1996; Hernández-Santana et al., 2008). $V_{s}$ is also higher under wetter conditions than under water-limited conditions (O'Grady et al., 2008) because lower soil water availability could increase hydraulic resistance between soil and root systems, preventing water movement from soil to plant leaves and triggering stomatal closure (Tognetti et al., 2009). The relationship between $V_{s}$ and environmental variables varies normally between species and scales. Limited by lower water availability and higher evaporative demand in arid environments, we hypothesized that larger threshold constrains on $V_{s}$ was a response of environmental variables at both hourly and daily scales for desert riparian forests.

Furthermore, hourly $V_{s}$ and daily $V_{s}$ could be estimated using synthetic environmental variables, and many of these driving environmental variables are highly correlated to one another. Previous studies have applied statistical approaches, including simple linear regression (Hultine et al., 2010) and multiple linear regression (Qu et al., 2007; Si et al., 2007), to estimate sap flow variations. O'Brien et al. (2004) used principle components analysis (PCA) to explore the underlying structure in multiple co-varying meteorological variables to estimate whole-tree sap flux, and applied a simple $\mathrm{S}$-shaped model and composite environmental index to estimate $V_{s}$ in tropical species. Moreover, for well-coupled forest canopies, $V_{s}$ could be estimated using some non-linear, multiplicative and independent functions (applied to modify through Jarvis-Stewart (JS) model) (Komatsu et al., 2006).

The modified JS model has been successfully applied to various types of forests (Dierick and Hölscher, 2009; Whitley et al., 2009; Han et al., 2012) with two to four factorial functions for canopy or stand transpiration. However, incongruent patterns in $V_{s}$ variations to driving variables complicate mechanisms related to the dynamics of whole-tree transpiration. Zeppel et al. (2004) reported an obvious hysteretic response of $V_{s}$ to photosynthetically active radiation $(P A R)$ and $V P D$. Moreover, hysteretic patterns that vary from a few minutes to several hours have a significant effect on relationships between hourly $V_{s}$ and daily $V_{s}$ and environmental variables (Oren et al., 1999). Zheng et al. (2014) indicated that the hysteretic response of evapotranspiration to temperature $\left(T_{a}\right)$ and VPD would cause certain uncertainties in simply evapotranspiration estimates. However, hysteresis is either eliminated or significantly reduced for half-hourly $V_{s}$ estimations when it is combined with $R_{S}$ and VPD in an evaporative demand index (O'Brien et al., 2004). Consequently, whether hysteretic influences the performance of sap flow models at a temporal scale remains uncertain.

In this study, we presented the results of $V_{s}$ of Populus euphratica, $R_{s}, V P D$ and soil water content $(S W C)$ from a field investigation during the growing season of 2012 in Northwest China. Our objectives were to: (1) detect the responses of $V_{s}$ to main environmental variables at both hourly and daily scales; (2) compare the performance of a simple linear model and a physically-based non-linear model to estimate hourly $V_{s}$ and daily $V_{s}$ of $P$. euphratica; and (3) evaluate the hysteretic responses of $V_{s}$ to $R_{s}$ and VPD. Our hypothesis was that a physically-based non-linear model which takes into account $R_{s}$ and VPD will provide direct and effective $V_{s}$ estimations during the growing season. Moreover, the hysteretic phenomenon between $V_{s}$ and environmental variables will play a key role in $V_{s}$ estimation. 


\section{Materials and methods}

\subsection{Study area}

This study was conducted at the Alxa Desert Eco-hydrology Experimental Research Station, Cold and Arid Regions Environmental and Engineering Research Institute, Chinese Academy of Sciences $\left(42^{\circ} 01^{\prime} \mathrm{N}, 101^{\circ} 21^{\prime} \mathrm{E} ; 884 \mathrm{~m}\right.$ asl) in the lower reaches of the Heihe River Basin, Northwest China. The region is characterized by a continental arid climate, with an average annual precipitation of $37.4 \mathrm{~mm}$, an average annual pan evaporation of $>3,390 \mathrm{~mm}$ and an annual average temperature of $8.2^{\circ} \mathrm{C}$. Prevailing wind directions are northwest in winter and spring, and southwest to south in summer and autumn. Annual average wind speed ranges from 3.4 to $4.0 \mathrm{~m} / \mathrm{s}$. Soil physical properties of the study area are provided in Table 1.

Table 1 Soil physical properties of the study area

\begin{tabular}{cccccc}
\hline \multirow{2}{*}{ Soil depth $(\mathrm{cm})$} & \multirow{2}{*}{ Soil bulk density $\left(\mathrm{g} / \mathrm{cm}^{3}\right)$} & \multicolumn{3}{c}{ Soil particle composition $(\%)$} & \multirow{2}{*}{ Soil field water capacity $\left(\mathrm{cm}^{3} / \mathrm{cm}^{3}\right)$} \\
\cline { 3 - 5 } & & Sand & Silt & Clay & 38.93 \\
\hline $0-10$ & 1.05 & 46.74 & 47.71 & 5.56 & 46.53 \\
$10-30$ & 1.43 & 49.17 & 43.86 & 6.97 & 11.39 \\
$30-50$ & 1.41 & 42.13 & 51.54 & 6.33 & 7.81 \\
$50-80$ & 1.28 & 28.45 & 63.86 & 7.69 & 32.92 \\
$80-120$ & 1.47 & 99.00 & 0.86 & 0.14 & 33.66 \\
$120-160$ & 1.54 & 25.37 & 70.80 & 3.83 & \\
\hline
\end{tabular}

The experimental field in this study is located at approximately $200 \mathrm{~m}$ southwest from the Alxa Desert Eco-hydrology Experimental Research Station. It is protected by a $100 \mathrm{~m} \times 100 \mathrm{~m}$ fenced enclosure. A detailed field inventory was conducted in July 2011. The dominant overstory species was $P$. euphratica, with the density of 146 trees $/ \mathrm{hm}^{2}$ and a canopy cover of approximate $42 \%$. The next dominant overstory species was Tamatix ramosissima with approximately 42 trees $/ \mathrm{hm}^{2}$. The understory species was dominated by grasses, including Sophra alopecutoides, Achnatherum splendens and Karelinia caspica. Groundwater depths ranged from 1.93 to $2.65 \mathrm{~m}$ during the experimental period (the growing season of 2012). Apart from precipitation, groundwater recharged from the Heihe River provided the main sources of water to sustain the regional ecosystems. The average age of $P$. euphratica forests was 120 years old, the average tree height was $11.17 \mathrm{~m}$, and the tree canopy dimensions in an east to west direction and in a south to north direction were 5.93 and $5.93 \mathrm{~m}$, respectively (Table 2). The average diameter at breast height $(\mathrm{DBH})$ was $45.90 \mathrm{~cm}$. The sapwood area $\left(S A, \mathrm{~cm}^{2}\right)$ was determined by the drilling method. In total, 66 cores were extracted from 66 trees based on DBH using an increment borer from which the sapwood empirical formula was established $\left(S A=1.27 \times \mathrm{DBH}^{1.43}\right)$. Thus, the average $S A$ was approximately $305.74 \mathrm{~cm}^{2}$.

Table 2 Height, diameter at breast height (DBH) and canopy diameter of trees in the enclosed P. euphratica site

\begin{tabular}{ccccc}
\hline & \multirow{2}{*}{ Height $(\mathrm{m})$} & DBH $(\mathrm{cm})$ & East-west & South-north \\
\cline { 3 - 5 } & & $45.90 \pm 14.38$ & $5.93 \pm 1.59$ & $5.93 \pm 1.68$ \\
Quadrat & $11.17 \pm 2.35$ & 43.4 & 5.3 & 7.8 \\
Tree 1 & 12.9 & 52.3 & 8.2 & 8.6 \\
Tree 2 & 12.6 & 47.3 & 6.4 & 8.8 \\
\hline
\end{tabular}

Note: Mean values of the quadart were calculated from 146 trees; and tree 1, tree 2 and tree 3 were selected as samples to monitor sap flow. Mean \pm SD.

\subsection{Sap flow measurements}

We selected three representatives of $P$. euphratica trees by means of tree height and DBH in the experimental field. We used heat ratio method (HRM) to determine the continuous $V_{s}$ during the growing season (June-September, day 168 to 276) of 2012. HRM was used for measuring the ratio of $T_{a}$ increase following the release of a pulse of heat at points equidistant downstream and upstream from center heater. A pair of copper-constantan thermocouples (HRM-30 sap flow 
sensors, ICT International Pty Ltd., Armidale, NSW, Australia) were symmetrically installed into the north facing of xylem tissues of stems (1.3-m height) $6 \mathrm{~mm}$ above and $6 \mathrm{~mm}$ below the center heater probe, respectively. Taking into account the radial distributions of sapwood, each thermocouple had two junctions to measure $V_{s}$, which were measured in xylem tissues at 7.5 and $22.5 \mathrm{~mm}$ depths from the tip of the needle. A metal guide was used to aid in drilling holes and minimize probe misalignment during insertion. Pulses were sent at an interval of $30 \mathrm{~min}$, and $T_{a}$ ratios were recorded continuously by a data logger (Smart Logger, ICT, Australia). We calculated the heat pulse velocity $\left(V_{h} ; \mathrm{cm} / \mathrm{h}\right)$ according to the method of Burgess et al. (2001):

$$
V_{h}=\frac{k}{x} \ln \left(\frac{v_{1}}{v_{2}}\right) \times 3600 .
$$

Where, $k\left(\mathrm{~cm}^{2} / \mathrm{s}\right)$ is the thermal diffusivity of fresh wood; $x(\mathrm{~cm})$ is the distance between the heater and the thermocouple; and $v_{1}$ and $v_{2}\left({ }^{\circ} \mathrm{C}\right)$ are the differences of the initial $T_{a}$ between the two thermocouples (downstream and upstream of the flow in relation to the position of the heater, respectively). $k$ was initially fixed at $2.50 \times 10^{3} \mathrm{~cm}^{2} / \mathrm{s}$, but this value was adjusted after we determined the thermal properties of wood $\left((2.98 \pm 0.21) \times 10^{3} \mathrm{~cm}^{2} / \mathrm{s}\right)$. All wound and misalignment corrections of probes were conducted according to Burgess et al. (2001), and the final $V_{s}$ was then calculated according to the method of Burgess et al. (2001).

\subsection{Soil volumetric water content and meteorological parameters}

Soil volumetric water content was monitored by multisensory frequency domain probes (EnviroSCAN; Sentek, Adelaide, Australia) at five soil depths (10, 30, 50, 80 and $140 \mathrm{~cm}$ ), and recorded at 10-min intervals using a CR1000 data logger (Campbell Inc., USA). Each capacity sensor was frequency-normalized by calibration against air and water in the laboratory to ensure the precision measurement (Yu et al., 2013). $R_{S}\left(\mathrm{~W} / \mathrm{m}^{2}\right)$ was measured using a pyranometer (CM5, Kipp \& Zonen, the Netherlands), and $T_{a}\left({ }^{\circ} \mathrm{C}\right)$ and relative humidity $(R H ; \%)$ were measured using a Rotronic Sensor (RS2, Rotronic, Switzerland). Additionally, VPD was determined by $T_{a}$ and $R H$ according to the method of Compbell and Norman (1998). Meteorological data, including $R_{s}, T_{a}$, $R H$ and precipitation were recorded by a data logger as mean values of 30-min intervals from an automatic meteorological station.

\subsection{Models for estimating $V_{s}$}

Physiological studies have shown that $V_{s}$ mainly depends on environmental variables, such as $R_{s}$, VPD and SWC (Si et al., 2007; Guan et al., 2012). In this study, we explored two approaches (multiple linear regression analysis (linear model) and modified non-linear JS model) to simulate the hourly $V_{s}$ and daily $V_{s}$. Firstly, the linear model was applied to associate $V_{s}$ to major environmental variables as follows:

$$
V_{s}=\mathrm{a}+\mathrm{b} R_{\mathrm{s}}+\mathrm{c} V P D .
$$

Where, $\mathrm{a}, \mathrm{b}$ and $\mathrm{c}$ are regression coefficients.

Secondly, the JS model was modified from an analytical model of stomatal conductance proposed by Jarvis (1976). Because of the simplicity and the direct calculation of stomatal conductance or canopy conductance as a function of environmental variables of this model, it has been widely used in soil-vegetation-atmosphere-transfer (SVAT) formulations (Oguntunde et al., 2007). Theoretically, stand water use could be calculated from canopy conductance by VPD for a well-coupled forest canopy. Thus, a modified JS model was used to calculate the recent canopy water use (Komatsu et al., 2006; Dierick and Hölscher, 2009; Köhler et al., 2009; Whitley et al., 2009; Han et al., 2012). In this case, $V_{s}$, which is similar to water use, was assumed to be calculated by $R_{S}$ and $V P D$ according to the following equation:

$$
V_{s}=V_{s-\max } \times f\left(R_{s}\right) \times f(V P D) \text {. }
$$

Where, $V_{s-\max }$ is defined as the maximum $V_{s}$ for each driving variable under non-limiting environmental conditions; and $f$ denoted a series of normalized response functions. Each of these functions had values between 0 and $1\left(0 \leq f_{i} \leq 1\right)$. To determine the response functions for $V_{s}$ in terms of its driving environmental variables, we assumed that the response of $V_{s}$ to each variable 
was independent of all the other variables when values for the other variables were not limiting.

Solar radiation $\left(R_{S}\right)$ response was determined by a hyperbolic-saturating function, which was applied to express the response of canopy transpiration to $R_{S}$ as follows (Komatsu et al., 2006; Whitley et al., 2009):

$$
f\left(R_{s}\right)=\left(\frac{R_{s}}{R_{m}}\right) \times\left(\frac{R_{m}+k_{1}}{R_{s}+k_{1}}\right) .
$$

Where, $R_{m}$ is an arbitrary radiation constant often fixed at $1,000 \mathrm{~W} / \mathrm{m}^{2}$; and $k_{1}\left(\mathrm{~W} / \mathrm{m}^{2}\right)$ is the curvature of the relationship between $V_{s}$ and $R_{s}$.

Vapor pressure deficit (VPD) response had three different expressions: (1) a strong S-shaped curve (O'Brien et al., 2004; Dierick and Kohler, 2009); (2) a new three-phrase response shape, which is similar to Boltzmann distribution (Whitley et al., 2009); and (3) an exponential saturation function (Kumagai et al., 2007; Du et al., 2011). We selected the S-shaped curve after a preliminary comparison between these three functions as follows:

$$
f(V P D)=1 /\left(1+\exp \left(\left(k_{2}-V P D\right) / k_{3}\right)\right) \text {. }
$$

Where, $k_{2}(\mathrm{kPa})$ is the $V P D$ from which $V_{s}$ increases to half of the maximum value $\left(R_{s}\right.$ non-limiting); and $k_{3}(\mathrm{kPa})$ is related to the slope. Parameters $k_{1}-k_{3}$ were optimized by minimizing the residual sum of squares using the Levenberg-Marquart algorithm (LMA) (Marquardt, 1963).

\subsection{Hysteretic response of $V_{s}$ to environmental variables}

Hysteretic effect occurred when an increase in a given independent variable does not cause the same variation in a dependent variable. We used cross-correlation coefficient plots between independent and dependent variables to identify their direct and inverse relationships at different time. Specifically, serial correlation coefficients were respectively calculated between 30-min mean $V_{s}$ observed at time $t$ and corresponding meteorological variables (both forward and backward time $t$ ) at a 30-min time step (for a total of 17 scenarios). When correlation coefficient between $V_{s}$ and each environmental variable reached optimum, time lags were then regarded as actual hysteresis. Rearranged environmental variables with hysteresis were then used to retrain and recalibrate the sap flow model. We named this method as "hysteresis calibration" in a subsequent study.

\subsection{Data sets and statistical analysis}

Measurements of $V_{s}$ were filtered to eliminate hours when $R_{S}$ was zero. This allowed us to only use daytime (07:00-19:00) sap flow and environmental data for modeling inputs. Days with rainfall were also excluded to avoid wet-canopy conditions. For evaluating the linear and JS models, the pre-selected measurement period (90 days) during the growing season was partitioned into two separate data sets of alternate days. Data of odd days (training data) were used to optimize response parameters of Eqs. 3-5, and data of even days (calibration data) were used to validate the model. No systematic patterns were evident in the data and no changes to model outputs occurred when allocation of each half of the data set to either optimization or validation days were reversed. Finally, root mean square error (RMSE) was used to weigh the deviation between observed value in the $i^{\text {th }}$ day $\left(y_{i}\right)$ and predicted value in the $i^{\text {th }}$ day $\left(\overline{y_{i}}\right)$ :

$$
\operatorname{RMSE}=\left(\frac{1}{n} \sum_{i=1}^{n}\left(y_{i}-\overline{y_{i}}\right)^{2}\right)^{\frac{1}{2}} \text {. }
$$

All procedures were conducted with the SPSS software 17.0 (SPSS Inc., USA) and SigmaPlot software 10.0 (Hearne Scientific Software Plc, Melbourne, Australia).

\section{Results}

\subsection{Variations in $V_{s}$ and environmental variables}

Significant differences were observed for the variations of $V_{s}$ and environmental variables during 
the growing season $(P<0.001, n=90$; ANOVA). Precipitation during the measurement period was $27.4 \mathrm{~mm}$ with only once large precipitation event $(15.4 \mathrm{~mm})$ occurring on day 206 . This large precipitation event increased SWC significantly at the depth of $0-140 \mathrm{~cm}$ by $13.5 \%$, while $S W C$ was increased slightly under the other precipitation events (Fig. 1). Average $T_{a}$ was $28.03^{\circ} \mathrm{C}$, which was consistent with the long-term average $T_{a}$ from June to September recorded at the Ejina meteorological station. Mean daily $V_{s}$ changed from $6.66 \mathrm{~cm} / \mathrm{h}$ on one rainy day (day 206) to $23.37 \mathrm{~cm} / \mathrm{h}$ on one rain-free day (day 216) and increased 3.5 folds during consecutive days. Daily $R_{s}$ ranged from 513.75 to $1,061.08 \mathrm{~W} / \mathrm{m}^{2}$, while mean daily $V P D$ varied from 0.41 to $5.66 \mathrm{kPa}$. Although the seasonal variations in $R_{s}$ and $V P D$ were similar to that in $V_{s}$ during most days, mismatching patterns also occurred on certain periods (Fig. 1).

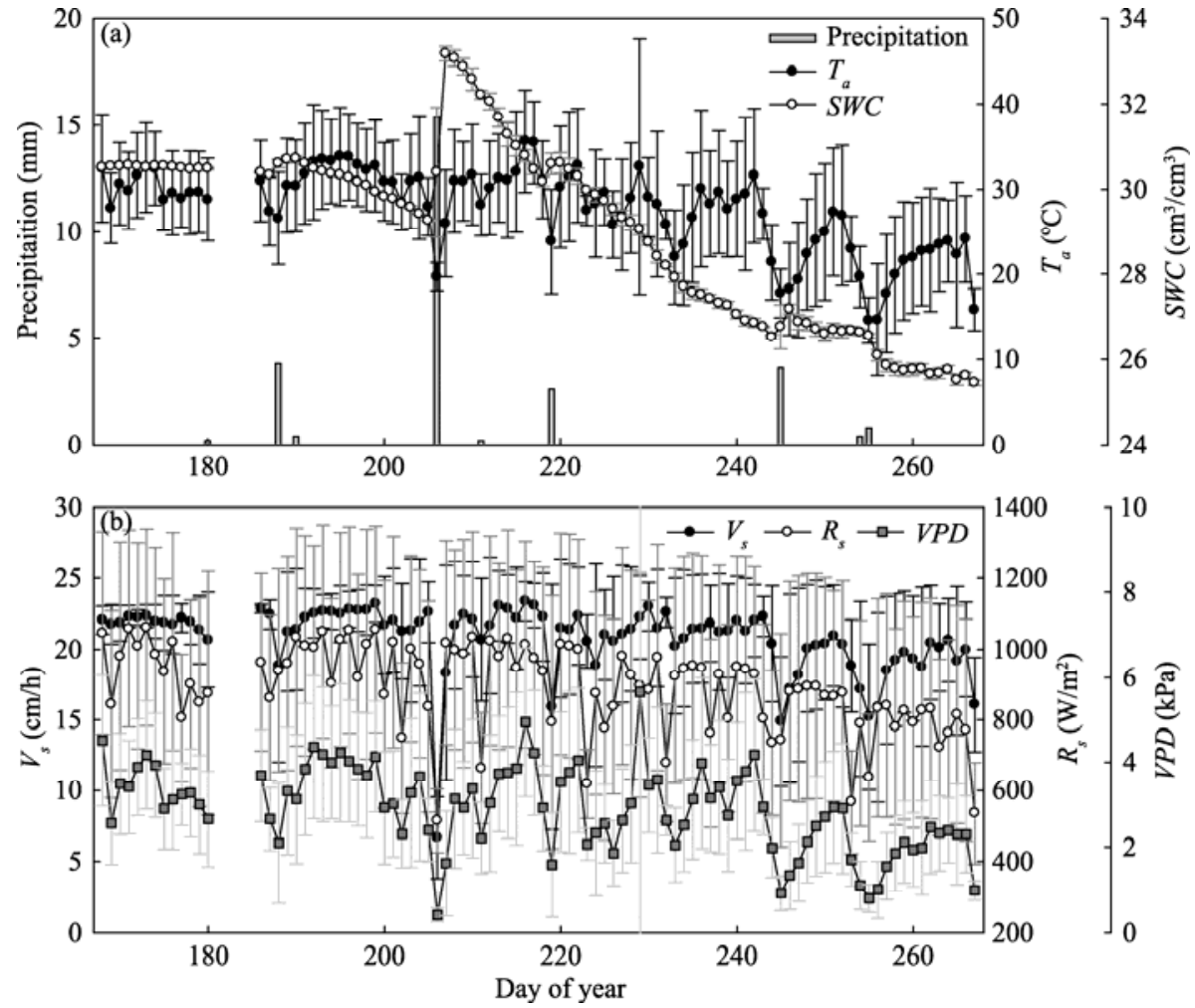

Fig. 1 Seasonal variations in (a) precipitation, temperature $\left(T_{a}\right)$ and soil water content (SWC), and (b) sap flow velocity $\left(V_{s}\right)$, solar radiation $\left(R_{s}\right)$ and vapor pressure deficit $(V P D)$ during the growing season of 2012. Error bar denotes standard deviation at a daily scale. Data between days 181 and 185 missed due to sensor damage.

\subsection{Response of $V_{s}$ to environmental variables}

At an hourly scale, $V_{s}$ was significantly correlated to all environmental variables $(P<0.01)$, with the correlation coefficients of $T_{a}>V P D>R_{s}>S W C$ (Table 3). For avoiding the potential effects of $T_{a}$ and VPD co-variation, we then used partial correlation analysis to determine that $R_{s}, V P D$ and $S W C$ were the main driving environmental variables. We found that $V_{S}$ was hyperbolic increased following the increasing $R_{s}$ until it reached approximately $600 \mathrm{~W} / \mathrm{m}^{2}$, from that further increasing in $R_{s}$ did not lead to corresponding increasing in $V_{s}$ (Fig. 2a). As evaporative demand increased, increasing VPD caused corresponding increases in $V_{s}$ for lower values of $V P D(<2 \mathrm{kPa})$, but for higher values of $V P D, V_{s}$ exhibited a stable trend with increasing VPD (Fig. 2b). Thus, a matching strong sigmoid ("S") curve was found between $V_{s}$ and $V P D$. Unfortunately, no clear correlations were found between $V_{s}$ and $S W C$ (Fig. 2c).

$V_{s}$ was also positively correlated with environmental variables (with the correlation coefficients of $V P D>T_{a}>R_{s}>S W C$ ) at a daily scale (Table 3). A hyperbolic-saturating function and a sigmoid function were shown between $V_{s}$ and $R_{s}$, and $V_{s}$ and $V P D$, respectively (Figs. $2 \mathrm{~d}$ and e). However, 
the saturation points of $R_{S}\left(900 \mathrm{~W} / \mathrm{m}^{2}\right)$ and $V P D(3.5 \mathrm{kPa})$ at a daily scale were greater than those at an hourly scale $\left(600 \mathrm{~W} / \mathrm{m}^{2}\right.$ for $R_{S}$ and $2 \mathrm{kPa}$ for $\left.V P D\right)$. SWC was weakly linearly correlated to $V_{s}$ (Fig. 2f). Thus, we selected $R_{s}$ and $V P D$ to analyze the response of $V_{s}$ to environmental variables at both hourly and daily scales.

Table 3 Correlation coefficients between $V_{s}$ and environmental variables during the growing season

\begin{tabular}{ccccc}
\hline & $R_{s}$ & $V P D$ & $T_{a}$ & $S W C$ \\
\hline Hourly $V_{s}$ & $0.651^{* *}$ & $0.772^{* *}$ & $0.791^{* *}$ & $0.336^{* *}$ \\
Daily $V_{s}$ & $0.545^{* *}$ & $0.830^{* *}$ & $0.822^{* *}$ & $0.388^{* *}$ \\
\hline
\end{tabular}

Note: ${ }^{* *}$ means significance at $P<0.01$ level. $V_{s}$, sap flow velocity; $R_{s}$, solar radiation; $V P D$, vapor pressure deficit; $T_{a}$, temperature; $S W C$, soil water content.
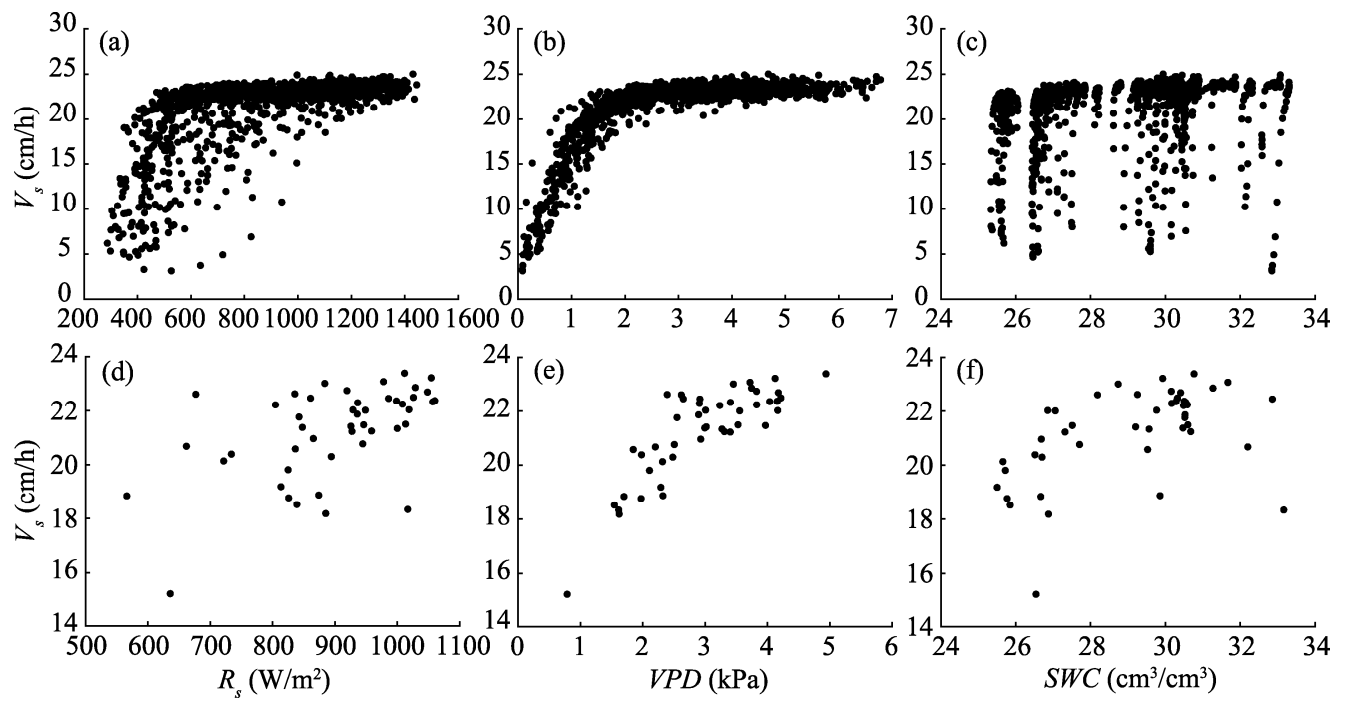

Fig. 2 Relationships of $V_{s}$ with (a) $R_{s}$, (b) VPD and (c) $S W C$ at an hourly scale; and (d) $R_{s}$, (e) $V P D$ and (f) $S W C$ at a daily scale based on experimental data

\subsection{Modeling $V_{s}$ based on environmental variables}

Compared to the linear model, the coefficient $\left(R^{2}\right)$ was higher but RMSE was lower for the JS model (Fig. 3). At an hourly scale, although $V_{s}$ was significantly overestimated between 07:00 and 08:00, it could be well-determined between 09:00 and 19:00 using the JS model (Fig. 3a). The slope, $R^{2}$ and RMSE of regression of observed $V_{s}$ and modeled $V_{s}$ generated by the JS model were $0.98,0.93$ and 1.07 , respectively, which were all higher than those generated by the linear model (Fig. 4a). At a daily scale, there was a slight underestimate of $V_{s}$ from 17 July to 27 July and from 13 August to 21 August for both models, which coincided with the relatively low VPD resulting from precipitation (Fig. 3b). However, compared to the linear model, the JS model showed stronger linear relationships between observed $V_{s}$ and modeled $V_{s}$. Specifically, $R^{2}$ and the slope for the JS model ( 0.91 and 0.99 , respectively) were higher than those for the linear model $(0.71$ and 0.83 , respectively), while RMSE for the JS model (0.49) was lower than that for the linear model (0.86; Fig. 4b). It demonstrated that seasonal variations in hourly $V_{s}$ and daily $V_{s}$ could be well-estimated using $R_{s}$ and $V P D$ through physically-based non-linear model.

\subsection{Hysteretic response of $V_{s}$ to environmental variables}

The maximum $V_{s}$ occurred either coincident with or later than the maximum $R_{s}$, and earlier than the maximum VPD (Fig. 5). At an hourly scale, the maximum $V_{s}$ occurred earlier than the maximum VPD by approximately $0.5 \mathrm{~h}\left(R^{2}=0.79\right)$ but later than the maximum $R_{s}$ by approximate $1.0 \mathrm{~h}\left(R^{2}=0.72\right.$; Fig. 6$)$. At a daily scale, the maximum $V_{s}$ lagged behind the maximum $V P D$ by approximately $2.5 \mathrm{~h}\left(R^{2}=0.84\right)$ but occurred earlier than the maximum $R_{S}$ by approximately $2 \mathrm{~h}$ $\left(R^{2}=0.56\right.$; Fig. 6). At an hourly scale, hysteretic response of $V_{s}$ to environmental variables unexpectedly weakened when $R_{S}$ and $V P D$ were combined together due to little increases in $V_{s-\max }$, 
$R^{2}$ and RMSE. At a daily scale, $R^{2}$ increased by approximately $2 \%(0.85$ to 0.88$)$ but RMSE decreased by approximately $10 \%(0.62$ to 0.56$)$ after $R_{s}$ and VPD hysteretic calibration, demonstrating a slightly improvement in analyzing the response of $V_{s}$ to environmental variables after taking the hysteretic response of $R_{s}$ and VPD into account (Table 4).
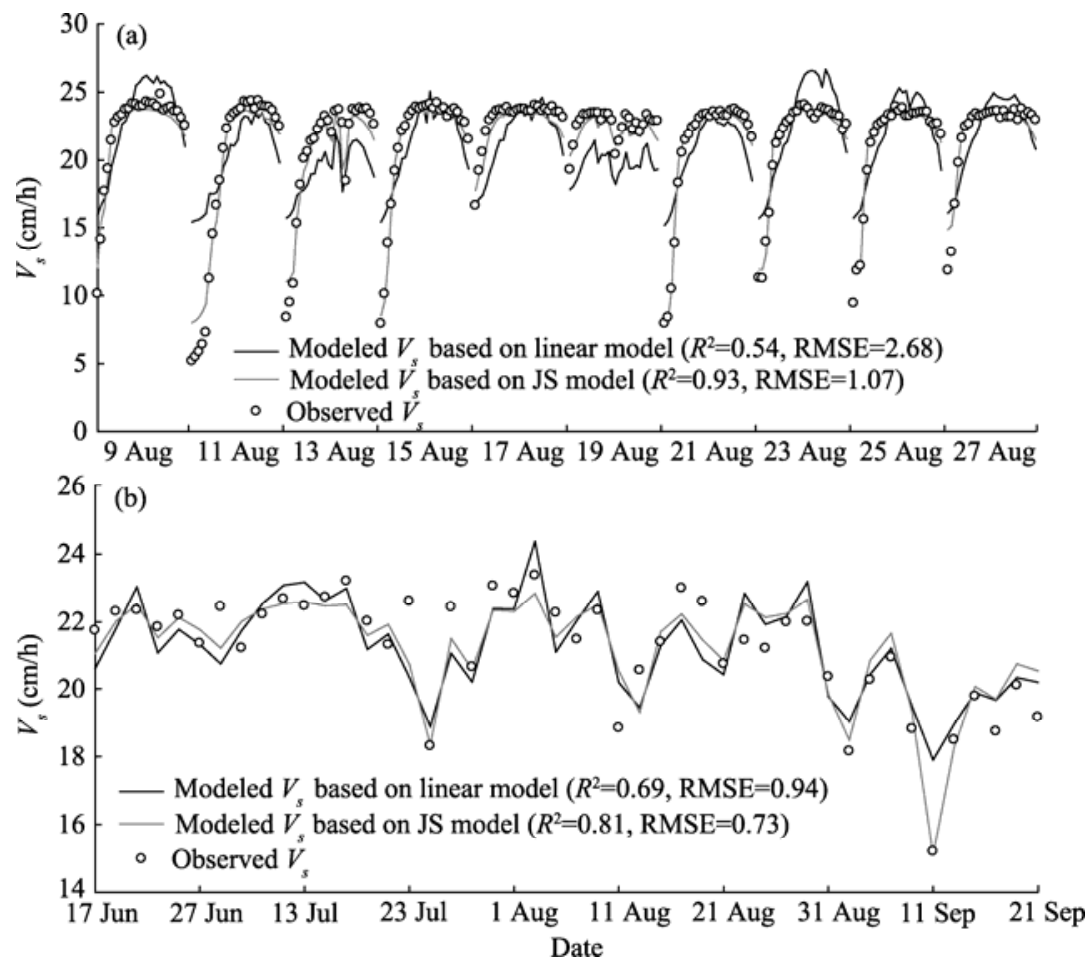

Fig. 3 Comparison between observed $V_{s}$ and modeled $V_{s}$ from the linear model and modified Jarvis-Stewart (JS) model for the training data sets in odd days (a) at an hourly scale (07:00-19:00) during 9-27 August 2012 and (b) at a daily scale from 17 June to 21 September, 2012. RMSE, root mean square error. Data in 29 June, 1 July, 3 July and 1 September were omitted due to rainfall events.
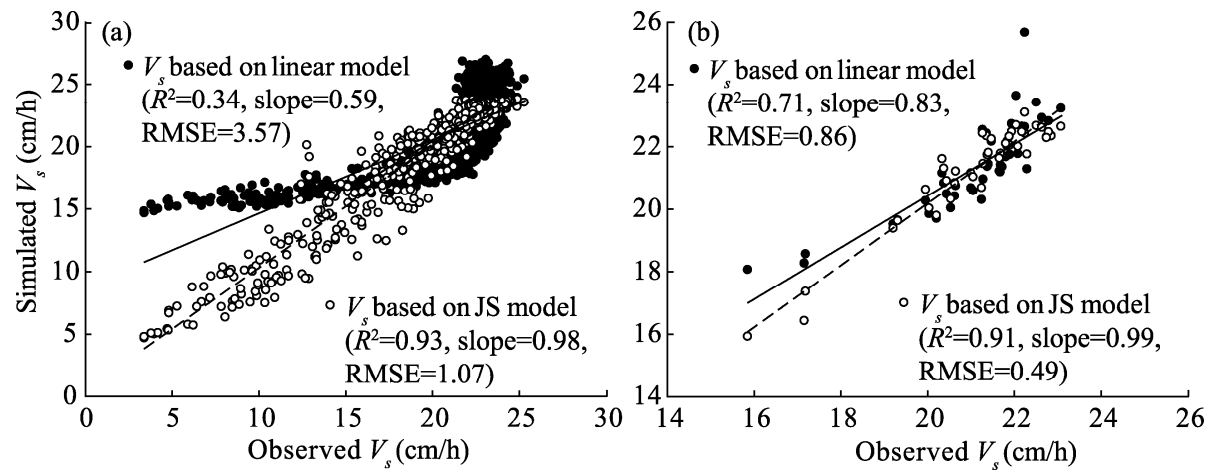

Fig. 4 Relationships between observed $V_{s}$ and modeled $V_{s}$ from the linear model and the modified JS model based on calibration data (a) at an hourly scale and (b) at a daily scale

\section{Discussion}

\subsection{Response of $V_{s}$ to environmental variables}

Seasonal variations in $V_{s}$ of $P$. euphratica were evident, and $V_{s}$ was significantly positively correlated to environmental variables during the growing season. Previous studies also showed good relationships between $V_{s}$ and $R_{s}$ for Artemisia ordosica (Huang et al., 2010), Salix 


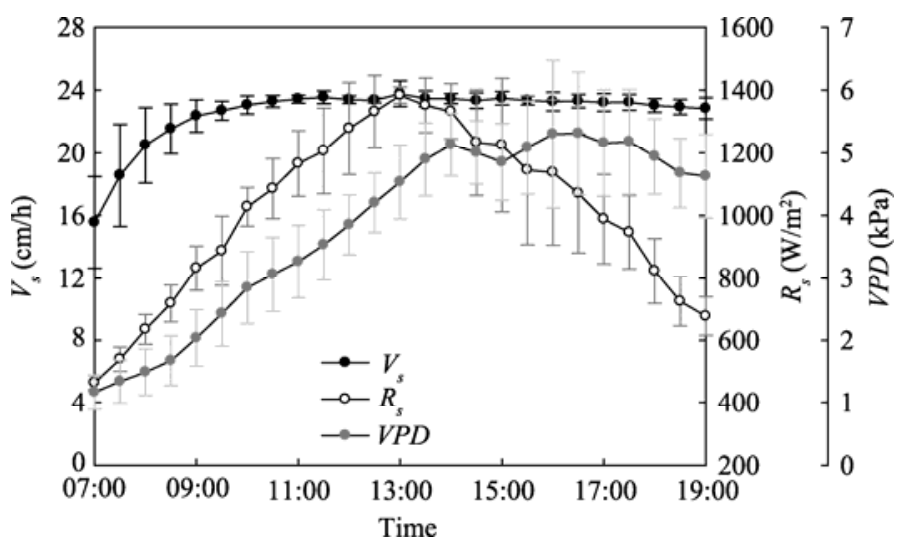

Fig. 5 Daily variations in $V_{s}, R_{s}$ and $V P D$ during 10 sunny days
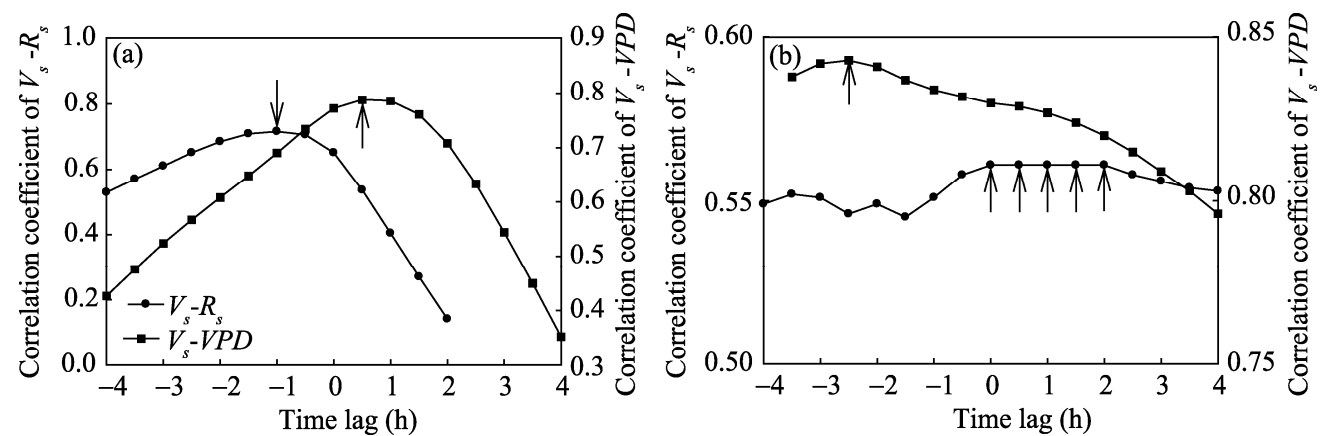

Fig. 6 Cross-correlation of $V_{s}$ with $R_{S}$ and VPD (a) at an hourly scale and (b) at a daily scale. Maximum correlation coefficient was retained as the time lag. Values in the horizontal axis higher than zero represent that the maximum $V_{s}$ occurs earlier than the maximum environmental variables, while values lower than zero represent that the maximum $V_{s}$ occurs later than the maximum environmental variables. The arrows indicate the maximum correlation coefficients.

Table 4 Comparison between parameter estimations from optimization of the modified Jarvis-Stewart (JS) model for a weighted non-linear least squares regime for non-hysteretic and hysteretic calibration

\begin{tabular}{cccccccc}
\hline Time scale & Calibration & $V_{s-\max }(\mathrm{cm} / \mathrm{h})$ & $k_{1}\left(\mathrm{~W} / \mathrm{m}^{2}\right)$ & $k_{2}(\mathrm{kPa})$ & $k_{3}(\mathrm{kPa})$ & $R^{2}$ & $\mathrm{RMSE}$ \\
\hline \multirow{2}{*}{ Hourly } & Non-hysteresis & $23.18 \pm 0.03$ & $82.33 \pm 3.39$ & $0.53 \pm 0.01$ & $0.43 \pm 0.01$ & 0.93 & 1.06 \\
& Hysteresis & $23.08 \pm 0.03$ & $84.83 \pm 3.91$ & $0.49 \pm 0.01$ & $0.40 \pm 0.01$ & 0.92 & 1.09 \\
\multirow{2}{*}{ Daily } & Non-hysteresis & $22.92 \pm 0.24$ & $-37.82 \pm 24.71$ & $0.14 \pm 0.11$ & $1.05 \pm 0.11$ & 0.85 & 0.62 \\
& Hysteresis & $23.94 \pm 0.22$ & $41.91 \pm 24.54$ & $-0.03 \pm 0.10$ & $0.88 \pm 0.09$ & 0.88 & 0.56 \\
\hline
\end{tabular}

Note: RMSE, root mean square error.

matsudana (Yin et al., 2014) and Haloxylon ammodendron (Zheng and Wang, 2014) in arid regions of Northwest China. However, for P. euphratica in this study, VPD was the dominant limiting factor to $V_{s}$ at both hourly and daily scales due to higher energy and water availability, and large $V P D$ ranges $(2-7 \mathrm{kPa})$ constrained $V_{s}$.

As increasing $R_{s}, V_{s}$ increased asymptotically. Hyperbolic saturating functions to plant water use or $V_{s}$ have been extensively applied (Komatsu et al., 2006; Whitley et al., 2009; Han et al., 2012). Different to linear relationship of $V_{s}$ and $R_{s}$ under wetter conditions (Rousseaux et al., 2009; Singer et al., 2010; Liu et al., 2012), $V_{s}$ tended to be stable when $R_{s}$ was in the neighborhood of 600 and $900 \mathrm{~W} / \mathrm{m}^{2}$ at hourly and daily scales under arid conditions in this study, respectively (Figs. 2a and d). David et al. (2004) reported a progressive loss in $V_{s}$ sensitivity to $R_{s}$ from morning to afternoon and attributed this phenomenon to transpiration saturation above a certain level of VPD by means of gradual stomatal closure. At low $R_{S}$ ranges, energy supplies limited evaporation; while at high $R_{S}$ levels, soil moisture and hydraulic resistance between soil and canopy limited evaporation (Whitley et al., 2009). 
The response of $V_{s}$ to VPD was more sensitive than that to $R_{s}$ (Table 3 ). $V_{s}$ exhibited a positive relationship with $V P D$ at lower levels $(<2 \mathrm{kPa})$, while for higher values of VPD $(2-7 \mathrm{kPa}), V_{s}$ showed a plateau-type response to $V P D$ at an hourly scale (Fig. 2e). The response of $V_{s}$ to increasing $V P D$ compared well with other studies that have found an alternative exponential saturation response, e.g. relationship between $V_{s}$ (or water use) and VPD for Camellia japonica in the Japanese cedar forest watershed on Kyushu Island, Japan (Kumagai et al., 2007) and between $V_{s}$ and co-variation of VPD and $R_{S}$ for Robinia pseudoacacia, Quercus liaotungensis and Abies sibirica in the Loess Plateau of China (Du et al., 2011). As VPD increasing, the two-phase behavior of $V_{s}$ was a feedback between increasing cuticular water loss and declining supply of water to guard cells which resulted in direct stomatal response to VPD. A low decoupling coefficient less than 0.2 indicated that $P$. euphratica was well coupled to the atmosphere and able to exert effective stomatal control over $V_{s}$ or transpiration in response to environmental stresses ( $\mathrm{Li}$ et al., 2013). Thus, for avoiding excessive water loss and maintaining water potential above a critical threshold, effective stomatal control and, hence, canopy conductance should be taken on preventing cavitations and irreversible loss of xylem functions (Bush et al., 2008; Tognetti et al., 2009). However, a new three-phase response of stand transpiration to VPD was found for Australia native woodland (dominated by Eucalyptus crebra and Callitris glaucophylla) in northwestern New South Wales of Australia (Whitley et al., 2009) and Platanus orientalis in the Tuqiaogou watershed of China (Han et al., 2012). $V_{s}$ (or stand scale transpiration) tended to increase and further reached the peak with increasing VPD, and then decreased with gradually increasing VPD later. Naithani et al. (2012) attributed this phenomenon to the stomatal regulation of transpiration for declining the root water supply. Thus strong stomatal regulation was taken effects to control the $V_{s}$ of $P$. euphratica as evaporative demand increasing. However, P. euphratica could use deep SWC and groundwater following well-developed root system to avoid declining hydraulic conductance from soil to atmosphere, therefore, $V_{s}$ remained at plateau level when undergoing high levels of $V P D(>2 \mathrm{kPa})$ in this study. Moreover, this could also be related to the sensitivity of desert species to VPD and leaf water potential. Finally, $V_{s}$ showed stable trend with increasing $V P D$ in the range of 2-3.5 $\mathrm{kPa}$ in this study, and this range was larger than those observed by Pataki and Oren (2003), Komastu et al. (2006), Oguntunde et al. (2007) and Han et al. (2012), but was similar to that observed by Whitley et al. (2009). This was probably because the site selected for our study was extremely dry, and experienced a large range of $V P D(0-7 \mathrm{kPa})$ and would recover from a long period of drought, compared to those mentioned above.

Bernier et al. (2002) and Ford et al. (2005) indicated that only under very low soil water availability did transpiration show a strong relationship with $S W C$. Lower soil water availability could increase hydraulic resistance between soil and root systems, prevent water movement from soil to plant leaves, and subsequently trigger stomatal closure, which in turn would obviously reduce transpiration rates (Tognetti et al., 2009). Moreover, Si et al. (2014) indicated that the main water source of $P$. euphratica was from the soil water in the subsoil layer $(140-180 \mathrm{~cm})$ and groundwater at a subsurface depth of 2.00-2.65 m. Thus, $V_{s}$ was slightly constrained by $S W C$ in this study due to the narrow range of $S W C$ and low groundwater availability during the growing season of 2012 (Figs. 2c and f).

\section{2 $V_{s}$ modeling and hysteretic calibration}

Compared to the linear model, the JS model could estimate the $V_{s}$ of $P$. euphratica more accurately for higher $R^{2}$ and lower RMSE values both at hourly and daily scales (Fig. 3). Previous studies have developed multiple linear models for analyzing the responses of $V_{s}$ to the main environmental variables, including $R_{s}, T_{a}, V P D$, wind speed and $S W C$ (Qu et al., 2007; Si et al., 2007). In this study, the linear model only explained $34 \%$ and $71 \%$ of $V_{s}$ variation at hourly and daily scales, respectively (Fig. 4). This was possibly caused by disregarding threshold constrains on $V_{s}$ from driving environmental variables and the interactions between these variables (Table 3 ). The JS model complied with the primary assumption in which driving environmental variables should be independent from each other, which was defined in the original JS model for estimating 
canopy conductance (Macfarlane et al., 2004). Observed hourly $V_{s}$ varied 4.8 folds over 10 sunny days in August 2012, and the JS model was able to follow the $V_{s}$ variations accurately (Fig. 3a). The JS model has been successfully used to estimate sap flux density or stand transpiration of Japanese Cryptomeria japonica trees (Komatsu et al., 2006), native Australian forests (Whitley et al., 2009), Indonesian Cacao and Gliricidia trees (Köhler et al., 2009) and Chinese Platycladus orientalis trees (Han et al., 2012). However, the JS model failed to detect the measured $V_{s}$ for low values of $R_{s}$ and VPD during the morning hours.

At an hourly scale, the maximum $V_{s}$ occurred earlier than the maximum VPD by approximately $0.5 \mathrm{~h}$ but later than the maximum $R_{s}$ by approximate $1.0 \mathrm{~h}$. At a daily scale, the maximum $V_{s}$ lagged behind the maximum VPD by approximately $2.5 \mathrm{~h}$ while occurred earlier than the maximum $R_{s}$ by approximately $2 \mathrm{~h}$. Lu et al. (2004) reported that understanding the hysteresis between $V_{s}$ and environmental variables was a solid foundation in identifying the mechanisms of $V_{s}$ and whole tree transpiration. Various generations of hysteresis occurring between $V_{s}$ (or transpiration) and environmental variables have been identified, including progressive (canopy) stomatal closure (Chen et al., 2011; Zheng et al., 2014), declining patterns in soil-to-canopy conductance at a daily scale (Zeppel et al., 2004), and stem water storage capacity (Kumagai et al., 2009). Thus, hysteretic effect could be considered as a means of plant self-protection in avoiding the overlapping of peak transpiration and the maximum meteorological variables to prevent excessive water extraction from stems (Chen et al., 2011). There were many previous studies demonstrated that sap flow (or water use) was mismatched with environmental variables (Oren et al., 1999; Ford et al., 2005), while a few studies discussed the effect of time lag on $V_{s}$ estimation. O'Brien et al. (2004) reported the morning hysteresis in $V_{s}$ response to $R_{s}$ and the afternoon hysteresis in $V_{s}$ response to $V P D$, and the result showed that hysteresis was either eliminated or significantly reduced when it was combined with $R_{S}$ and VPD as the evaporative demand index. Oguntunde et al. (2007) ignored hysteretic effects in transpiration modeling due to the synchronicity of transpiration and potential transpiration. An alternative autoregressive integrated moving average (ARIMA) time series model (with orders of 3, 1 and 1) for synthetic photosynthetically active radiation, VPD and SWC emphasized the importance of hysteresis in hydrological processes related to canopy transpiration modeling (Ford et al., 2005). Unexpectedly, there were no improvements in hourly $V_{s}$ estimations and only a slight enhancement in daily $V_{s}$ estimations using the JS model after hysteretic calibration in this study (Table 4). This can be partly explained by the fact that the combination of morning hysteresis that related to $V_{s}-R_{S}$ and afternoon hysteresis that related to $V_{s}-V P D$ would eliminate or reduce the mismatched patterns between $V_{s}$ and synthetic environmental variables as a whole.

\section{Conclusions}

In this study, we examined the relationships between $V_{s}$ and main environmental variables and found that $V_{S}$ of $P$. euphratica was driven by $R_{s}, V P D$ and $S W C$ with an order of $V P D>R_{s}>S W C$ at both hourly and daily scales. Obvious threshold constraints of $R_{s}$ and VPD on $V_{s}$ were observed, and they exhibited hyperbolic-saturating and sigmoid functions, respectively, especially at an hourly scale. A multiple linear regression and a newly modified JS model were then used to model $V_{S}$ according to the responses of $V_{S}$ to $R_{S}$ and $V P D$ at both hourly and daily scales during the growing season of 2012. Compared to the linear model, the JS model could estimate the $V_{s}$ variations more accurately. Although significant hysteresis in $V_{s}-R_{s}$ and $V_{s}-V P D$ relationships was found at both hourly and daily scales, no significant improvements in $V_{s}$ estimation were detected after hysteretic calibration. This indicated that hysteretic response of $V_{s}$ to environmental variables would be eliminated when taking the time lag in the morning (for $V_{s}-R_{s}$ ) and afternoon (for $V_{s}-V P D$ ) into account together. These findings will help us understand the comprehensive mechanisms of seasonal patterns of $V_{s}$ at hourly and daily scales, as well as provide new insights into evaluating the contribution of $P$. euphratica trees to water use for desert riparian ecosystems in the Heihe River Basin. 


\section{Acknowledgements}

This study was supported by the National Natural Science Foundation of China (91425301, 91025024), the Key Project of Chinese Academy of Sciences (KZZD-EW-04-05) and the West Light Foundation of Chinese Academy of Sciences.

\section{References}

Bernier P Y, Bréda N, Granier A, et al. 2002. Validation of a canopy gas exchange model and derivation of a soil water modifier for transpiration for sugar maple (Acer saccharum Marsh.) using sap flow density measurements. Forest Ecology and Management, 163(1-3): 185-196.

Burgess S S O, Adams M A, Turner N C, et al. 2001. An improved heat pulse method to measure low and reverse rates of sap flow in woody plants. Tree Physiology, 21(9): 589-598.

Bush S, Pataki D E, Hultine K R, et al. 2008. Wood anatomy constrains stomatal responses to atmospheric vapor pressure deficit in irrigated, urban trees. Oecologia, 156(1): 13-20.

Chen L X, Zhang Z Q, Li Z D, et al. 2011. Biophysical control of whole tree transpiration under an urban environment in Northern China. Journal of Hydrology, 402(3-4): 388-400.

Compbell G S, Norman J M. 1998. An Introduction to Environmental Biophysics. New York: Springer, 37-75.

David T S, Ferreira M I, Cohen S, et al. 2004. Constraints on transpiration from an evergreen oak tree in southern Portugal. Agricultural and Forest Meteorology, 122(3-4): 193-205.

Dierick D, Hölscher D. 2009. Species-specific tree water use characteristics in reforestation stands in the Philippines. Agricultural and Forest Meteorology, 149(8): 1317-1326.

Dragoni D, Caylor K K, Schmid H P. 2009. Decoupling structural and environmental determinants of sap velocity. Part II. Observational application. Agricultural and Forest Meteorology, 149(3-4): 570-581.

Du S, Wang Y L, Kume T, et al. 2011. Sapflow characteristics and climatic responses in three forest species in the semiarid Loess Plateau region of China. Agricultural and Forest Meteorology, 151(1): 1-10.

Ford C R, Coranson C E, Mitchell R J, et al. 2005. Modeling canopy transpiration using time series analysis: A case study illustrating the effect of soil moisture deficit on Pinus taeda. Agricultural and Forest Meteorology, 130(3-4): 163-175.

Granier A, Huc R, Barigah S T. 1996. Transpiration of natural rain forest and its dependence on climatic factors. Agricultural and Forest Meteorology, 78(1-2): 19-29.

Guan D X, Zhang X J, Yuan F H, et al. 2012. The relationship between sap flow of intercropped young poplar trees (Populus $\times$ euramericana cv. N3016) and environmental factors in a semiarid region of northeastern China. Hydrological Processes, 26(19): 2925-2937.

Han L, He K N, Hu X B, et al. 2012. Canopy transpiration response to environmental variations in Platycladus orientalis: properties and modelling. Pakistan Journal of Botany, 44(2): 541-545.

Hernández-Santana V, Dacid T S, Martínez-Fernández J. 2008. Environmental and plant-based controls of water use in a Mediterranean oak stand. Forest and Ecology Management, 255(11): 3707-3715.

Huang L, Zhang Z S, Li X R. 2010. Sap flow of Artemisia ordosica and the influence of environmental factors in a revegetated desert area: Tengger Desert, China. Hydrological Processes, 24(10): 1248-1253.

Hultine K R, Nagler P L, Morino K, et al. 2010. Sap flux-scaled transpitaion by tamarisk (Tamarix spp.) before, during and after episodic defoliation by the saltcedar leaf beetle (Diorhabda carinulata). Agricultural and Forest Meteorology, 150(11): 1467-1475.

Jarvis P G. 1976. The interpretation of the variations in leaf water potential and stomatal conductance found in canopies in the field. Philosophical Transactions of the Royal Society B: Biological Sciences, 273(927): 593-610.

Köhler M, Dierick D, Schwendenmann L, et al. 2009. Water use characteristics of cacao and Gliricidia trees in an agroforest in Central Sulawesi, Indonesia. Ecohydrology, 2(4): 520-529.

Komatsu H, Kang Y, Kume T, et al. 2006. Transpiration from a Cryptomeria japonica plantation part 2: responses of canopy conductance to meteorological factors. Hydrological Processes, 20(6): 1321-1334.

Kumagai T, Aoki S, Shimizu T, et al. 2007. Sap flow estimates of stand transpiration at two slope positions in a Japanese cedar forest watershed. Tree Physiology, 27(2): 161-168.

Kumagai T, Aoki S, Otsuki K, et al. 2009. Impact of stem water storage on diurnal estimates of whole-tree transpiration and canopy conductance from sap flow measurements in Japanese cedar and Japanese cypress trees. Hydrological Processes, 23(16): 2335-2344.

Li W, Si J H, Feng Q, et al. 2013. Response of transpiration to water vapour pressure defferrential of Populus euphratica. 
Journal of Desert Research, 33(5): 1377-1384. (in Chinese)

Liu C W, Du T S, Li F S, et al. 2012. Trunk sap flow characteristics during two growth stages of apple tree and its relationships with affecting factors in an arid region of northwest China. Agricultural Water Management, 104: 193-202.

Lu P, Urbab L, Zhao P. 2004. Granier's thermal dissipation probe (TDP) method for measuring sap flow in trees: theory and practice. Acta Botanica Sinica, 46(6): 631-646. (in Chinese)

Macfarlane C, White D A, Adams M A. 2004. The apparent feed-forward response to vapour pressure deficit of stomata in droughted, field-grown Eucalyptus globulus Labill. Plant, Cell \& Environment, 27(10): 1268-1280.

Marquardt D W. 1963. An algorithm for least-squares estimation of non-linear parameters. Journal of the Society for Industrial and Applied Mathematics, 11: 431-441.

Naithani K J, Ewers B E, Pendall E. 2012. Sap flux-scaled transpiration and stomatal conductance response to soil and atmospheric drought in a semi-arid sagebrush ecosystem. Journal of Hydrology, 464-465: 176-185.

O’Brien J J, Oberbauer S F, Clark D B. 2004. Whole tree xylem sap flow responses to multiple environmental variables in a wet tropical forest. Plant, Cell \& Environment, 27(5): 551-567.

O'Grady A P, Worledge D, Battaglia M. 2008. Constraints on transpiration of Eucalyptus globulus in southern Tasmania, Australia. Agricultural and Forest Meteorology, 148(3): 453-465.

Oguntunde P G, van de Giesen N, Savenije H H G. 2007. Measurement and modelling of transpiration of a rain-fed citrus orchard under subhumid tropical conditions. Agricultural Water Management, 87(2): 200-208.

Oren R, Phillips N, Ewers B E, et al. 1999. Sap-flux-scaled transpiration responses to light, vapor pressure deficit, and leaf area reduction in a flooded Taxodium distichum forest. Tree Physiology, 19(6): 337-347.

Pataki D E, Oren R. 2003. Species differences in stomatal control of water loss at the canopy scale in a mature bottomland deciduous forest. Advance in Water Resources, 26(12): 1267-1278.

Qu Y P, Kang S Z, Li F S, et al. 2007. Xylem sap flows of irrigated Tamarix elongata Ledeb and the influence of environmental factors in the desert region of Northwest China. Hydrological Processes, 21(10): 1363-1369.

Rousseaux M C, Figuerola P I, Correa-Tedesco G, et al. 2009. Seasonal variations in sap flow and soil evaporation in an olive (Olea europaea L.) grove under two irrigation regimes in an arid region of Argentina. Agricultural Water Management, 96(6): 1037-1044.

Sánchez-Costa E, Poyatos R, Sabaté S. 2015. Contrasting growth and water use strategies in four co-occurring Mediterranean tree species revealed by concurrent measurements of sap flow and stem diameter variations. Agricultural and Forest Meteorology, 207: 24-37.

Si J H, Feng Q, Zhang X Y, et al. 2007. Sap flow of Populus euphratica in a desert riparian forest in an extreme arid region during the growing season. Journal of Integrative Plant Biology, 49(4): 425-436.

Si J H, Feng Q, Cao S K, et al. 2014. Water use sources of desert riparian Populus euphratica forests. Environmental Monitoring and Assessment, 186(9): 5469-5477.

Singer J W, Heitman J L, Hernandez-Ramirez G, et al. 2010. Contrasting methods for estimating evapotranspiration in soybean. Agricultural Water Management, 98(1): 157-163.

Steppe K, De Pauw D J W, Doody T M, et al. 2010. A comparison of sap flux density using thermal dissipation, heat pulse velocity and field deformation methods. Agricultural and Forest Meteorology, 150(7-8): 1046-1056.

Tognetti R, Giovannelli A, Lavini A, et al. 2009. Assessing environmental controls over conductances through the soil-plant-atomsphere continuum in an experimental olive tree plantation of southern Italy. Agricultural and Forest Meteorology, 149(8): 1229-1243.

Whitley R, Medlyn B, Zeppel M, et al. 2009. Comparing the Penman-Monteith equation and a modified Jarvis-Stewart model with an artificial neural network to estimate stand-scale transpiration and canopy conductance. Journal of Hydrology, 373(1-2): 256-266.

Yin L H, Zhou Y X, Huang J T, et al. 2014. Dynamics of willow tree (Salix matsudana) water use and its response to environmental factors in the semi-arid Hailiutu River catchment, Northwest China. Environmental Earth Sciences, 71(12): 4997-5006.

Yu T F, Feng Q, Si J H, et al. 2013. Patterns, magnitude, and controlling factors of hydraulic redistribution of soil water by Tamarix ramosissima roots. Journal of Arid Land, 5(3): 396-407.

Zeppel M J B, Murray B R, Barton C, et al. 2004. Seasonal responses of xylem sap velocity to VPD and solar radiation during drought in a stand of native trees in temperate Australia. Functional Plant Biology, 31(5): 461-470.

Zheng C L, Wang Q. 2014. Water-use response to climate factors at whole tree and branch scale for a dominant desert species in central Asia: Haloxylon ammodendron. Ecohydrology, 7(1): 56-63.

Zheng H, Wang Q F, Zhu X J, et al. 2014. Hysteresis responses of evapotranspiration to meteorological factors at a diel timescale: Patterns and Causes. PLoS ONE, 9(6): e98857, doi: 10.1371/journal.Pone.0098857. 